\title{
Evaluation of the effect of operational condition parameters on the large-scale V-ASP performance and system regulation measures
}

\author{
Jiajia Yuan ${ }^{1, a}$, Wenyi Dong ${ }^{1, b}$ and Feiyun Sun ${ }^{1, c}$ \\ ${ }^{1}$ Harbin Institute of Technology Shenzhen Graduate School, Shenzhen Key Laboratory of Water \\ Resource Utilization and Environmental Pollution Control, Shenzhen 518055, China \\ ayuanjiajia1990@126.com, bdwy1967@qq.com, c'sunfeiyun1982@gmail.com
}

\begin{abstract}
Keywords: Vegetation-activated sludge process (V-ASP); large-scale; COD and Nitrogen removal; robust regulation; vegetation characteristics

Abstract. The effect of seasonal temperature fluctuation, organic loading rate shocking and aeration intensity change on the performance of large-scale vegetation-activated sludge process (V-ASP) was evaluated, and effective system regulation measures were proposed. Vegetation characteristics, including photosynthetically active radiation, transpiration ratio and stomatal conductance were also monitored before and after regulation measures implemented. The temperature-proof measures in low winter improved the sludge activity, vegetation characteristics and rhizosphere microorganism function, which helped the effluent $\mathrm{COD}$ and $\mathrm{NH}_{4}{ }^{+} \mathrm{N}$ meet Chinese wastewater discharge standards stably. By increased the sludge recirculation ratio from 0.5 to 0.75 to resist organic loading rate shocking, the pollutions removal as well as the vegetation activities were improved greatly. As for the instable aeration intensity in varied unit, switch between continuous feeding and pulse feeding effectively enhanced the $\mathrm{NH}_{4}{ }^{+}-\mathrm{N}$ removal capability.
\end{abstract}

\section{Introduction}

Vegetation-activated sludge process (V-ASP) is a new configured system for decentralized wastewater treatment. The system combined activated sludge processes, such as Sequencing Batch Reactor (SBR), Anaeroxic-Anoxic-Oxic $\left(\mathrm{A}^{2} / \mathrm{O}\right)$, Contact Oxidation Process (COP), with decontaminated wetland vegetation like Canna indica, Dracaena sanderiana and Cyperus alternifolius, which intended to use in tourist resort, school yard, small village and residential area. The lab-scale V-ASP has operated for a long term, which has been confirmed to have consistently stable higher removal efficiencies of organic substances and nutrients compared with traditional ASP [1]. Vegetation could remove pollutions through its vegetation transpiration ratio and provide great surface for microorganism activity enhancement, thus, achieve a high COD and nutrients removal performance in planted systems [2]. Therefore, it is considered as an indispensable part of the V-ASP in our past study. In order to apply V-ASP to practical engineering, a large-scale V-ASP was built in Zhengzhou, Henan province to treat schoolyard wastewater. During the operation, effect of operational condition parameters, such as seasonal temperatural fluctuation, organic loading rate shocking and aeration intensity change on V-ASP performance need to be evaluated. This paper was to evaluate these effects, and operational parameters system regulations measures applied on the three problems. The vegetation characteristics were also determined before and after regulations to estimate its impact on vegetation and vegetation's contribution to pollutions removal.

\section{Materials and Methods}

Anoxic/Oxic (A/O) process was used to form the large-scale V-ASP and its working volume was $686 \mathrm{~m}^{3}$ (Anoxic tank: $\mathrm{L} \times \mathrm{W} \times \mathrm{H}=7.0 \times 4.3 \times 5.7 \mathrm{~m}$; Oxic tank: $\mathrm{L} \times \mathrm{W} \times \mathrm{H}=7.0 \times 12.9 \times 5.7 \mathrm{~m}$ ). The HRT of anoxic and oxic part was $5 \mathrm{~h}$ and $15 \mathrm{~h}$, respectively. The reactors were installed with assembly semi-soft media which were constructed by plastic ring and synthetic fiber string. Canna indica $(C I)$ and Cyperus altrnlifolius $(C A)$ were immersed into oxic tank and the cultivation density were about 180 $\mathrm{cm}^{2} /$ vegetation and their root beneath water level not less than $15 \mathrm{~cm}$. 
The chemical oxygen demand (COD) and ammonia $\left(\mathrm{NH}_{4}{ }^{+}-\mathrm{N}\right)$ in influents and effluents were evaluated after filtration by $0.4-\mu \mathrm{m}$ black polycarbonate membrane filters according to standard analytical methods (APHA, 1989). Temperature and DO were examined by YSI-550A probe (U.S. YSI Company). The vegetation characteristics, including photosynthetically active radiation (PAR), transpiration ratio ( $\mathrm{Tr})$ and stomatal conductance (Gs) were measured on mature $C I$ leaves use a portable transpiration system (SY-1023, China).

\section{Results and Discussion}

\section{Effect of seasonal temperatural fluctuation}

In winter, especially in cold area, there is always a problem in wastewater treatment using biological technology, for the low efficiency and the high difficulty to reach the criterion, which is also existed in V-ASP. As the V-ASP is constructed in glass house, series of temperature-proof measures were applied, including sealing windows and doors, in-situ heat utilization of equipment operation and radiant energy using during noon time. After adoption of these temperature-proof measures, indoor average temperature could be increased from $2-3^{\circ} \mathrm{C}$ to $8-9^{\circ} \mathrm{C}$. The change of COD and $\mathrm{NH}_{4}{ }^{+}-\mathrm{N}$ treatment performance was presented in Fig.1 (a). The average COD effluent and removal rate were 62 $\mathrm{mg} / \mathrm{L}$ and 33.90\% before insulation, which could not reach China GB18918-2002 urban sewage treatment plant discharge standards. Significant decline was found in COD effluent with the average value reached $28 \mathrm{mg} / \mathrm{L}$ after insulation. Similar to the COD removal, the average effluent $\mathrm{NH}_{4}{ }^{+} \mathrm{N}$ concentration and removal efficiency reduced to $0.55 \mathrm{mg} / \mathrm{L}$ from $6.53 \mathrm{mg} / \mathrm{L}$ and $89.21 \%$ from $53.26 \%$ under the action of temperature-proof measures. Three reasons may explain for this phenomenon. Firstly, the sludge activity in V-ASP increased as the temperature raised. Activated sludge functional microorganism groups including heterotrophs, nitrifiers and denitrifiers took lead responsibility for $\mathrm{COD}$ and $\mathrm{NH}_{4}{ }^{+}-\mathrm{N}$ removal. Trapani et al. proved that temperature plays a key role in the nitrification activity and low temperature could reduce nitrifiers activities [3]. Secondly, vegetation, as an indispensable decontaminated unit in V-ASP also greatly influenced by temperature. Low temperature is considered as one of the most key environmental factors that restricts plants growth and photosynthesis. Fig. 1(b) and (c) indicated that three vegetation characteristic parameters, especially PAR, increased greatly after insulation. Three parameters are closely related to plants growth, which increased with the elevation of temperature. Similar to other study, we agreed that the pollution removal directly related to plant growth [4]. Therefore, raising temperature increased the pollutions removal proportion by the vegetation uptake in V-ASP. Finally, microorganism in rhizosphere, which an essential part of the system pollutants removal, had a significant positive correlation with temperature. Peng et al. also found that temperature was of great importance to the nitrogen bacteria, particularly ammonia-oxidizing bacteria and nitrite-oxidizing bacteria [5].

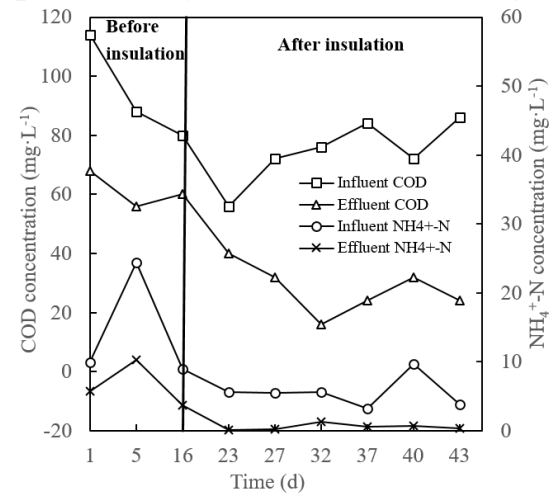

(a)

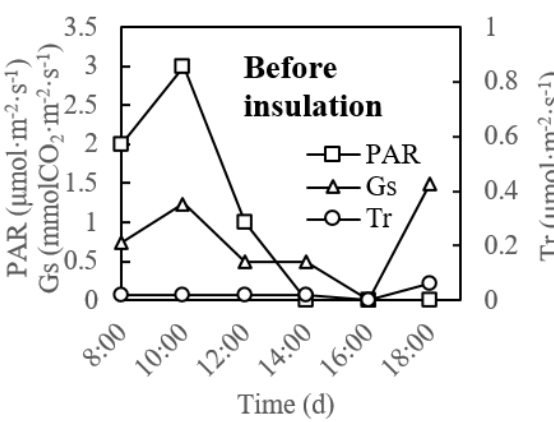

(b)

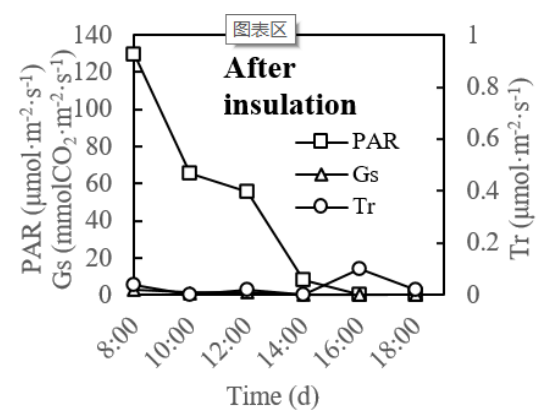

(c)

Fig. 1 The performance of V-ASP and vegetation characteristic before and after insulation. (a) COD and $\mathrm{NH}_{4}{ }^{+}-\mathrm{N}$ concentration; (b) PAR, Gs and Tr of $C I$ before insulation; (c) PAR, Gs and Tr of $C I$ after insulation. 


\section{Effect of organic loading rate shocking}

The V-ASP influent was domestic sewage from campus, which could suddenly increase during semester beginning for the increase flow of people. The volumetric load of COD increased to 0.932 $\mathrm{kgCOD} /\left(\mathrm{m}^{3} \cdot \mathrm{d}\right)$ from $0.233 \mathrm{kgCOD} /\left(\mathrm{m}^{3} \cdot \mathrm{d}\right)$. The solution for this situation was to adjust the sludge reflux ratio from 0.5 to 0.75 . The treatment performance before and after regulation were summarized in Fig.2(a). The influent COD jumped up to $400 \mathrm{mg} / \mathrm{L}$ and the effluent value is $108 \mathrm{mg} / \mathrm{L}$ before regulation, which could not meet the national discharge standards. After regulation measures, the effluent COD reached a stable level under $50 \mathrm{mg} / \mathrm{L}$. A $\mathrm{NH}_{4}{ }^{+}-\mathrm{N}$ loading shock happened in the late-stage up to $48.73 \mathrm{mg} / \mathrm{L}$. Under the effect of control measures, the average effluent $\mathrm{NH}_{4}{ }^{+}-\mathrm{N}$ reached $4.70 \mathrm{mg} / \mathrm{L}$. As the sludge reflux ratio increased, nitrate carried by nitrifying liquid was also increased, which could enhance denitrification thus improve COD removal. On account of the large number COD degraded in anoxic stage by denitrifying bacteria, the influent of oxic part contained small amount of organic matter and large amount of $\mathrm{NH}_{4}{ }^{+}-\mathrm{N}$. Due to the lack of organic matter as carbon source, heterotrophic bacteria were weak in the competition with autotrophic nitrification bacteria. Therefore, the nitrifying bacteria with slow proliferation rate became the predominant bacterium in aerobic stage in the presence of large amounts $\mathrm{NH}_{4}{ }^{+}-\mathrm{N}$, which promoted the removal efficiency of $\mathrm{NH}_{4}{ }^{+}-\mathrm{N}$ with other conditions unchanged. When control measure did not adopt, the average Tr of $C I$ in $\mathrm{V}$-ASP was $0.082 \mu \mathrm{molH}_{2} \mathrm{O} /\left(\mathrm{m}^{2} \cdot \mathrm{s}\right)$ and the value raised to $0.418 \mu \mathrm{molH} \mathrm{H}_{2} \mathrm{O} /\left(\mathrm{m}^{2} \cdot \mathrm{s}\right)$ after regulation as shown in Fig.2(b) and (c). Plant characteristics associated with the adhesion of microorganism amount in rhizosphere [6]. After adjust the sludge reflux ratio, the mixed liquor suspended solids (MLSS) in oxic tank increased, accordingly, raised the rhizosphere microorganism, therefor, enhanced plant physiological activity.

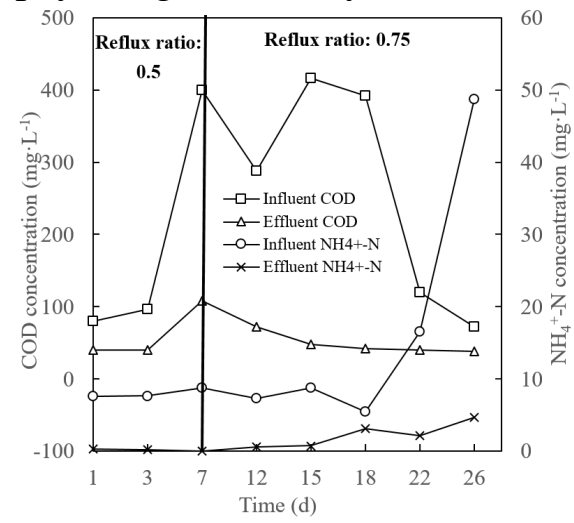

(a)

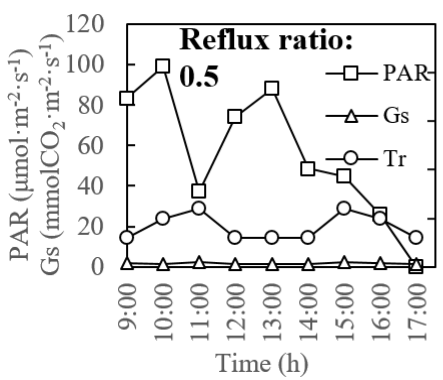

(b)

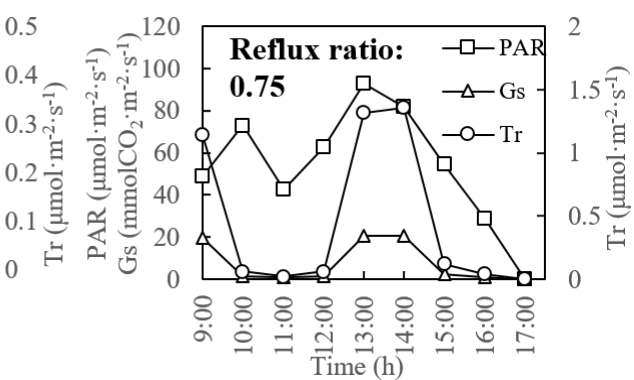

(c)

Fig.2 The performance of V-ASP and vegetation characteristic before and after regulation under organic loading rate shocking condition. (a) $\mathrm{COD}$ and $\mathrm{NH}_{4}{ }^{+}-\mathrm{N}$ concentration; (b) PAR, Gs and Tr of $C I$ before regulation; (c) PAR, Gs and Tr of $C I$ after regulation.
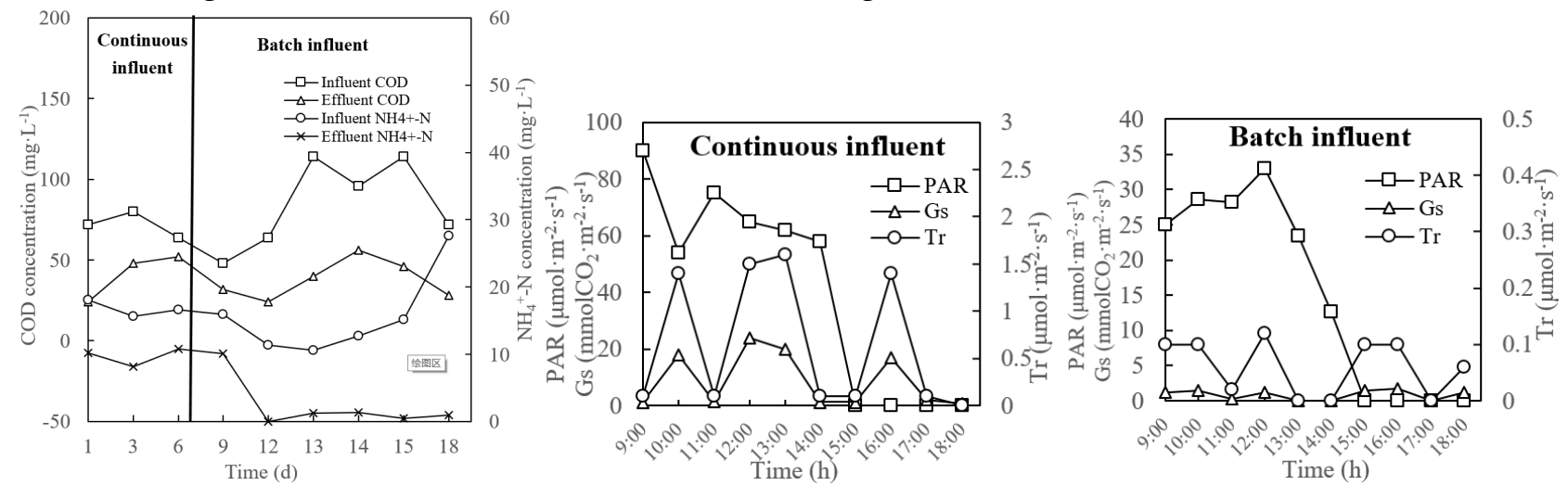

Fig.3 The performance of V-ASP and vegetation characteristic before and after regulation under aeration intensity fluctuation condition. (a) $\mathrm{COD}$ and $\mathrm{NH}_{4}{ }^{+}-\mathrm{N}$ concentration; (b) PAR, Gs and $\mathrm{Tr}$ of $C I$ before regulation; (c) PAR, Gs and Tr of $C I$ after regulation. 


\section{Effect of instable aeration intensity}

In practical engineering, instable aeration in oxic zone was always occurred. During the V-ASP operation, dissolved oxygen (DO) in oxic tank dropped from $4.5 \mathrm{mg} / \mathrm{L}$ to $2 \mathrm{mg} / \mathrm{L}$ and has fluctuated. In such case, we took the measure of change influent modes and transformed continuous feeding to pulse feeding. The COD and $\mathrm{NH}_{4}{ }^{+}-\mathrm{N}$ influent and effluent concentrations are illustrated in Fig.3(a). The regulation made the COD removal more stable and average $\mathrm{NH}_{4}{ }^{+}-\mathrm{N}$ effluent droped from $9.82 \mathrm{mg} / \mathrm{L}$ to $0.83 \mathrm{mg} / \mathrm{L}$, which satisfied the discharge criterion. The major reason for the removal efficiency increasing was that batch influent extended the hydraulic retention time and reduced the organic loading, hence, microorganism in V-ASP have relatively sufficient capacity and time to consume organic matter and nutrients. For vegetation in V-ASP, the reducing of PAR, Gs and Tr was presented in Fig.3(b) and (c). We assumed that vegetation and its rhizosphere microorganism have direct relationship with oxygen and the contention was supported by Allen et al. and Mei et al. [7, 8].

\section{Conclusion}

Effect of operational condition parameters on the large-scale V-ASP system performance was evaluated and effective system regulation measures were proposed. Temperature-proof measures used in low temperature could enhance sludge activity and plant characteristics of V-ASP. The organic loading rate shocking effect could be adjusted by increase the sludge recirculation ratio from 0.5 to 0.75, which resulted high COD and $\mathrm{NH}_{4}{ }^{+}-\mathrm{N}$ removal efficiency in V-ASP. As for DO changed in oxic zone, V-ASP treatment performance could be maintained by switch between continuous feeding to pulse-feeding mode.

\section{Acknowledgements}

This work was financially supported by the key laboratory improvement plan (JCYJ20130402100505795) and grants 2012ZX07313001-008 from water pollutant control and treatment the National Water Pollution Control and Treatment Science and Technology Major Project(2012ZX07313001-008).

\section{References}

[1]Yuan J.J., Dong W.Y., Sun F.Y., Li P., Zhao K.: An ecological vegetation-activated sludge process (V-ASP) for decentralized wastewater treatment: system development, treatment performance, and mathematical modeling. Environ. Sci. Pollut. Res.(2016) DOI 10.1007/s11356-016-6259-3

[2] Chen Y., Wen Y., Zhou Q., Vymazal J.: Effects of plant biomass on nitrogen transformation in subsurface-batch constructed wetlands: a stable isotope and mass balance assessment. Water Res. Vol. 63 (2014), p. 158-167

[3] Trapani D.D., Christensson M., Torregrossa M., Viviani G.: Performance of a hybrid activated sludge/biofilm process for wastewater treatment in cold climate region: Influence of operating conditions. Biochem. Eng. J. Vol. 77 (2013), p. 214-219

[4] Carballeira T., Ruiz I., Soto M.: Effect of plants and surface loading rate on the treatment efficiency of shallow subsurface constructed wetlands. Ecol. Eng. Vol. 90(2016), p. 203-214

[5] Peng L., Hua Y.M., Cai J.B., Zhao J.W., Zhou W.B., Zhu D.W.: Effects of plants and temperature on nitrogen removal and microbiology in a pilot-scale integrated vertical-flow wetland treating primary domestic wastewater. Ecol. Eng. Vol. 64(2014), p. 285-290

[6] Salvato M., Borin M., Doni S., Macci C., Ceccanti B., Marinari S., Masciandaro G.: Wetland plants, micro-organisms and enzymatic activities interrelations in treating $\mathrm{N}$ polluted water. Ecol. Eng. Vol. 47(2012), p. 36-43

[7] Allen J.G., Beutel M.W., Call D.R., Fischer A.M., Effects of oxygenation on ammonia oxidation potential and microbial diversity in sediment from surface-flow wetland mesocosms. Bioresource Technol. Vol. 101(2010), p. 1389-1392 
[8] Mei X.Q., Yang Y., Tam N.F.Y., Wang W.Y., Li L., Roles of root porosity, radial oxygen loss, Fe plaque formation on nutrient removal and tolerance of wetland plants to domestic wastewater. Water Res. Vol. 50(2014), p. 147-159 